\title{
Strengthening Community Participation in the Integrated Development Planning Process for Effective Public Service Delivery in the Rural Limpopo Province
}

\author{
Kgalema Mashamaite \\ Department of Development Planning and Management, University of Limpopo \\ andani.madzivhandila@ul.ac.za \\ Andani Madzivhandila \\ Department of Development Planning and Management, University of Limpopo \\ kgalema.mashamaite@ul.ac.za
}

Doi:10.5901/mjss.2014.v5n25p225

\begin{abstract}
The purpose of this paper is to evaluate the participation of local communities in the integrated development planning process with the hope of enhancing the provision of public services in the Limpopo Province. Legislations on developmental local government in South Africa provide provisions for local communities to participate in the integrated development planning process within their municipalities to ensure that the provision of public services is effective. Municipalities are constitutionally required to develop five year integrated development plans (IDPS) for strategic, inclusive and responsive governance of the municipality which allows effective participation of local communities in the development planning. Thus, it is a requirement for and the responsibility of municipalities to ensure that local communities participate adequately and effectively in the integrated development planning process. The paper argues that despite the provisions for local communities to participate in the development planning processes, communities are still, in most cases, over-looked and shut out of the development planning processes. As such, the application of community participation as an approach to effective and sustainable delivery of public services needs reinforcement. The paper concludes that lack of participation by local communities remains pervasive in rural settings such as those in the Limpopo Province. This is attested to by the prevailing poor socio-economic conditions as well as the violent public service delivery protests in rural areas.
\end{abstract}

Keywords: Community participation; integrated development planning; service delivery; integrated development plan; developmental local government

\section{Introduction}

Participation is considered as one of the key tenets of democratic governance in South Africa. Municipal councils are obliged to develop a culture of municipal governance that shifts from strict representative government to participatory governance, and must for this purpose, encourage, and create conditions for residents, communities and other stakeholders in the municipality to participate in local affairs (Ababio, 2004). In addition, the White Paper on Local Government states that Local government structures must develop strategies and mechanisms to continuously engage with citizen's, businesses and community groups and offers the following options amongst others; focus group participatory action research to generate detailed information about a wide range of specific needs and values; and participatory budget initiatives aimed at linking community priorities to capital investment programme (Buccus, Hemson, Hicks \& Piper, 2007)

The deepening of local democracy in South Africa is embedded in wide-ranging regulative provisions that oblige organs of the state in general and municipalities in particular to establish mechanisms and processes for public participation. The Municipal Systems Act 32 of 2000 and Municipal Structures Act 117 of 1998 lay down formal measures to establish a coherent system of developmental local governance resting on pillars of community participation, integrated development planning (IDP), budgeting; and performance management. The preparation of IDPs, in particular, has become a mantra to communities, managers and political representatives at all levels of government as an all-embracing planning tool which will allow municipalities to address wide ranging developmental challenges, through participation, in a systematic and sustainable manner. In addition to general provisions for participation municipalities are also given specific obligations to consult in a prescribed manner through legislation (Brynard, 1996). The advertising of the annual 
tariffs and rates, forming part of the budget is prescribed. When municipalities are considering alternative service delivery mechanisms they must consult their communities. Despite the provisions for local communities to participate in the development planning processes, communities are still, in most cases, over-looked and shut out of the development planning processes. Hence, there is a need to reinforcement the application of community participation as an approach to effective and sustainable delivery of public services. On that note, the purpose of this paper is to evaluate the participation of local communities in the integrated development planning process with the hope of enhancing service delivery in the Limpopo Province.

\section{Community Participation in South Africa: A Legal Requirement}

The Constitution of the Republic of South Africa (Act 106 of 1996) envisages a robust local government system, which can provide democratic and accountable government for local communities; ensure the provision of services to communities in a sustainable manner; promote social and economic development; promote a safe and healthy living environment; and encourage the involvement of communities and community organisations in the matters of local government. The Municipal Systems Act 32 of 2000 is part of a series of legislation which aims to empower local government to fulfil its constitutional obligations. In 1998 the government issued a Local Government White Paper on Local Government outline a policy framework for local government. Later that year government passed the Municipal Demarcation Act 27 of 1998, which enabled the re-demarcation of municipal boundaries; and the Municipal Structures Act, which defined the structures of local government. The Municipal Systems Act complement these pieces of legislation, by regulating key municipal organisational, planning, participatory and service delivery systems. National government has also enacted the Municipal Financial Management Bill, which regulates municipal financial matters. Together, these pieces of legislation provide a framework for a democratic, accountable and developmental local government system, as envisaged by the Constitution.

After the White Paper established, the Local Government Municipal Demarcations Act 27 of 1998 was introduced. The Municipal Demarcations Act made provision for the re-demarcation of municipal boundaries and establishment of the Municipal Demarcations Board (MDB) tasked with demarcating Municipal boundaries in accordance with a set of factors in the Act. The demarcation process, as provided for by the Demarcations Act, led to the reduction of municipalities in South Africa from 843 to 284 . This was aimed at increasing manageability and functionality, among other things. The Demarcations Act was followed by the introduction of the Local Government Municipal Structures Act (117 of 1998). The Municipal Structures Act provided for the establishment of municipalities in accordance with the requirements relating to categories and types of municipality. The Act sets a criterion for determining the category of municipality to be established in an area, for defining the types of municipality within each category and for an appropriate division of functions and powers between categories of municipality. This Act also made provision for internal regulatory systems, structures and office bearers of municipalities. In addition, the Structures Act provides for appropriate electoral systems.

Another important legislation to be promulgated, which laid a framework for the local government system, was the Local Government Municipal Systems Act 32 of 2000. The Systems Act, as it is known, provides for the core principles, mechanisms, and processes that are necessary to enable municipalities to move progressively towards the social and economic upliftment of local communities, and ensure universal access to essential services that are affordable to all. The Act, notably, provides for community participation as a means to bring about service delivery. In essence, all legislations make provision for the involvement and participation of communities in municipal affairs through the integrated development planning process.

\section{Factors Affecting Meaningful Participation of Communities}

\subsection{Lack of education and civic apathy}

Most community members are not sufficiently informed to participate meaningfully in municipal government. This makes municipal councilors and officials less willing to consider the views of community. Also the majority of members of the community are not clear about the role of a municipality. According to Ababio (2004: 14), the question may be asked whether the community is really competent to participate in municipal issues that would influence them directly, especially planning issues. Cameron (2002: 28) state that, a large proportion of the population do not vote, not so much because of governmental restrictions but because of lack of personal interest. Furthermore, while the average resident may identify strongly with his town, he/she does not identify with his/her town council. Another contributing factor may be the tendency to write local government rules and regulation into laws using language that is not readily understood the communities. 


\subsection{Lack of public accountability}

Lack of public accountability is usually a direct result of lack of transparency. Ababio (2004: 278) believes that, a general dislike for and suspicion for community participation exists among public officials. Cameron (2002: 26) goes further by stating that, the concept of public accountability in current municipal administration is weak to the point of being nonexistent. Ababio (2004: 278) states that, the present system of accountability in the country has several inherent flaws. According to Ababio (2004: 278), municipal chief officials, together with councilors, are responsible for policy decisions and the allocation of scarce resources. However, chief officials are not effectively held responsible and accountable to the public. Cameron (2002: 23) prescribes that the municipal councilors should display a sense of responsibility and accountability when performing their duties. Therefore, accountability should be internal, that is, subordinates are answerable to a superior, and external authority, making each official accountable to the public. Once these two mechanisms are formally established, high ethical standards of behaviour can be demanded from all public functionaries.

\subsection{Non-representativeness}

The local sphere is an arena where the community can participate in matters that affect their welfare, thereby shaping their own living environment. Common sense suggests that individuals are more likely to participate in smaller municipalities than in large municipalities. However, Section D of the White Paper on Local Government (1998:62) argues that this is not the case in South Africa. The notion that small local government units promote community participation does not necessarily enhance everyone's democratic rights because the unwillingness to participate is more common than the frustration of not getting a response to their demands. The different parties involved in community participation are not always competent, articulate and well organised and women are not adequately represented. Therefore, a significant number of women never identify their needs and problems with their municipality. The provision of essential services is the primary component of a municipality (Brynard, 1996). The community as the recipients of municipal services often complains that the services provided are not up to standard and do not really address their needs and aspirations.

\section{Integrated Development Planning: A Developmental Mandate for Local Municipalities}

Prior to 1994, local government in South Africa was mainly concerned with service provision and the implementation of regulations, however, with the introduction of the new Constitution and new legislative and policy frameworks, the role of local government expanded to a large extent (Subban \& Theron, 2012; Department of Provincial Local Government (DPLG), 2001/2003). Municipalities are now required to be developmental in their approach and activities (DPLG, 2001/2003; Valeta, 2008). For municipalities to become developmental in nature, they have to change the way that they work. One of the tools that municipalities must apply to assist them to be developmental is the Integrated Development Planning (IDP). Integrated Development Planning (IDP) is a planning method to assist municipalities to develop a coherent, long-term plan for the co-ordination of all development and delivery in their area of jurisdiction (White Paper on Local Government (WPLG), 1998; Mautjana \& Mtapuri, 2014). Municipalities are not only required to meet the present needs of communities but must ensure that they make informed projections about and anticipate future demands in order to ensure effective, efficient and sustained service delivery over the short, medium and long term (DPLG, 2001/2003). The IDP has since become synonymous with the new democratic government development planning model to respond to socio-economic challenges facing local governments in South Africa (Subban \& Theron, 2012; Mautjana \& Mtapuri, 2014). The new role for local government included the provision of basic services, creation of jobs, promoting democracy and accountability and eradication of poverty.

The IDP is a more flexible, people-centred strategic planning process through which local municipalities develop their integrated development plans (IDPs) in order to address socio-economic challenges facing communities within their jurisdiction (WPLG, 1998; DPLG, 2001/2003; Mautjana \& Mtapuri, 2014). The inception of the IDP, as a development management tool, represented transformation of the local government towards a more developmental one. Municipalities no longer only have the task of providing basic local administration but are now expected to play an important role in the country's struggle against poverty and underdevelopment. A municipality is developmental if it is able to deliver such as the provision of household infrastructure and services such as water, sanitation, local roads, storm water drainage, refuse collection and electricity. IDP brings together various economic, social, environmental, legal, infrastructural and spatial aspects of a problem or plan (DPLG, 1999/2004; Mello \& Maserumule, 2010). This should take place in a way that enhances development and provides sustainable empowerment, growth and equity for the short, medium and long term 
planning of a municipality. Additionally, the IDP is a critically important management tool to help transformation, growth and development at local government level.

Integrated development planning (IDP) is a process through which municipalities prepare a strategic plan containing short, medium and long-term development objectives, strategies and programmes for the municipal area (Mashamba, 2008; Valeta, 2008; Phago, 2009; Mautjana \& Mtapuri, 2014). According to the Municipal Systems Act 32 of 2000 all municipalities have to undertake an integrated development planning process to produce integrated development plans (IDPs). Hence, the integrated development plans (IDPs) are the product of the integrated development planning process and is seen as the principal instrument that guides and informs budgeting, management and decision-making related to service delivery and development in a municipality (Mafunisa \& Maphunye, 2008; Valeta, 2008; Phago, 2009). Furthermore, the IDP is a mechanism intended to fast-track service delivery by ensuring a well-informed, speedy and sustainable decision-making process through involving all role players in the implementation of projects (DPLG, 2001/2003; Mashamba, 2008). Thus, the IDP as a legislative requirement has a legal status and supersedes all other plans that guide development at local government level. Thus, developing IDPs is a legal requirement according to Municipal Systems Act 32 of 2000, however, that is not the only reason why municipalities must prepare the plans. The Constitution of the Republic of South Africa (Act 106 of 1996) assigns a clear developmental role to local government in Sections 152 and 153. Under the Constitution, municipalities have been awarded major developmental responsibilities to ensure that the quality of life for all citizens is improved and sustainable. The IDPs enable municipalities to manage the process of fulfilling the developmental mandate as articulated in the Constitution and WPLG.

In addition to ensuring that all citizens have access to at least a minimum level of basic services, municipalities must now also take a leading role in addressing poverty and inherited inequities, and in promoting local economic and social development and democracy (DPLG, 2001/2003). Thus, service delivery should not merely be aimed at present demands, but municipalities are also required to make informed projections about and anticipate future demands in order to ensure effective, efficient and sustained service delivery over the short, medium and long term. Through the IDP, municipalities are informed about the problems affecting their communities and, being guided by information on available resources, are able to develop and implement appropriate strategies and projects to address the problems. Therefore, the IDP is one of the key tools for local government to cope with its new developmental role (Malefane \& Mashakoe, 2008). In contrast to the role planning has played in the past, integrated development planning is now seen as a function of municipal management, as part of an integrated system of planning and delivery (DPLG, 2001/2003). The IDP process is meant to arrive at decisions on issues such as municipal budgets, land management, promotion of local economic development and institutional transformation in a consultative, systematic and strategic manner (Mashamba, 2008). The IDPs, however, not only inform the municipal management but they are also supposed to guide the activities of any agency from the other spheres of government, corporate service providers, NGOs and the private sector within the municipal area. Thus, integrated development planning is a very interactive and participatory process which requires involvement of a number of stakeholders. IDP is a process by which the planning efforts of different spheres and sectors of government and other institutions are co-ordinated at local government level (Geyer, 2006; Mello \& Maserumule, 2010; Maloka \& Mashamaite, 2013). Because of the participatory nature of IDP, often municipalities take longer to complete their IDPs within the municipal budgeting cycle. However, during this period delivery and development is not at a standstill, it continues. The IDP is reviewed annually which results in the amendment of the plan should this be necessary (DPLG, 2001/2003).

\section{Community Participation in the Integrated Development Planning Processes: A Quest for Effective Service Delivery}

The dawn of a new democratic state in South Africa required the developmental local government in the country to develop and adopt strategic, creative and integrated approach to governance of municipalities with the aim of addressing challenges associated with service delivery and meeting basic needs of the citizens. As such the government of South Africa adopted a people-centred approach in order to curb the development inadequacies and injustices of the past (Tshabalala and Lombard, 2009; Maloka \& Mashamaite, 2013). This required active partnerships between the public and private sectors as well as the rest of the civil society to participate in the development planning of local communities for effective delivery of public services. The notion is to promote a participatory approach to development within municipalities in the country. Hence, local governments as agents of development are legally mandated and required to involve local communities and stakeholders in the promotion of social and economic development in order to meet their needs and improve their quality of life.

Mzimakwe \& Reddy (2008); Siyongwana \& Mayekiso (2011); Govender \& Reddy (2011) emphasise that the 
municipalities must ensure participation of local communities by developing appropriate strategies and mechanisms such as forums of organised formations, structured stakeholder participation in council committees, participatory action research, with specific focus groups and formation of associations. This means that participation should be a structured process rather than a process of public mass meetings used to advance personal interests (Mzimakwe \& Reddy, 2008). Municipalities are not only expected to find ways of structuring participation, but must also become active in encouraging and promoting participation particularly of marginalised groups. Thus, the IDP process is regarded as an ideal management tool to promote and enforce participation of communities on issues that affect them. Paradoxically, no procedures are prescribed for the participation of communities in the integrated development planning process. The only prescribed tool for promotion of participation, however, is the dissemination of information on mechanisms and matters of participation, on rights and duties of residents and on municipal governance issues in general (Mzimakwe \& Reddy, 2008). Participation of communities in the IDP process is only one of several arenas of participatory interaction between local government and citizens. Other means of ensuring participatory local government include offering people choices between services, citizen and client-oriented ways of service delivery and public administration, partnership between communities/stakeholder organisations and local authorities in implementation of projects, and giving residents the right of petition and complaint and obliging municipal government to respond.

The developmental local government in South Africa require municipalities to involve local communities in the municipal processes within their area of jurisdiction (WPLG, 1998; Municipal Sytems Act, 2000). One of these processes is the integrated development planning (IDP). The IDP process should allow adequate and effective participation of local communities in the development planning of municipalities. Hence, the participation of communities in the IDP process plays an essential and integral role to the provision of public services and ensures that municipalities are accountable, transparent, responsive, effective and efficient. Community participation in the IDP process provide ordinary citizens with the platform to voice out their concerns, needs and aspirations in the prioritisation of municipal services concerning development in their communities (Njenga, 2009). Hence, meaningful participation and involvement of communities play a crucial role in ensuring effective service delivery within municipalities. Community participation is critical in a quest to address the needs of the citizens in an efficient and effective manner and as the cornerstone for strengthening local democracy.

\section{Conclusion}

The developmental role of municipalities in South Africa is clearly articulated by various pieces of legislations. Municipalities have been identified as playing a pivotal role of ensuring that the needs of communities are effectively responded to in a participatory manner. Participation in the municipality's development processes is a constitutional right of communities and residents. In essence, municipalities are legally required to create conditions for participation of communities in municipal matters and, over and above encourage participation through the IDP process. Previously, many participation processes in the IDP process were organised in a way which did not comply with any of the general principles stated in the White Paper on Local Government. As a result, municipalities in South Africa are faced with many challenges including the encouragement of the communities, organisations and stakeholders in municipal matters.

Currently, most communities are excluded or are unwilling to involve themselves in matters that affect their lives at municipal level. Hence, effective strategies need to be formulated to engage community participation in enhancing service delivery within municipalities. Additionally, the ever increasing challenges facing municipalities to improve service delivery requires innovative and effective methods and systems that will address the needs of the community and ensure that communities meaningfully participate. Thus, the IDP is a municipal intervention identified to ensure that effective service delivery interactions with communities are achieved. In essence, the involvement and participation of communities, in the matters of the municipality, through the IDP process, is meant to promote local democracy and fasttrack service delivery effectively and efficiently. According to Public Service Commission (2008), the involvement of communities in matters of service delivery is imperative in a democratic state by entrenching local democracy and promoting social cohesion between the state and community. Meaningful participation requires active and direct involvement of the communities in matters that affect their well-being and in ensuring effective service delivery (Ababio, 2004).

\section{References}

Buccus, I, Hemson, D. Hicks, J and Piper, L. 2007. Public participation and local governance. Centre for Public Participation.

Ababio, E.P. 2004. Enhancing community participation in developmental local government for improved service delivery. Journal of 
Public Administration, 39(2): 272-289

Cameron, R. 2002. Local Government: Quo Vadis? Journal of Public Administration, 37(4): 475-491.

Brynard, D.J. 1996. Public participation in local government and administration: bridging the gap. Politeia 15(2).

Department of Provincial and Local Government (DPLG). 2001/2003. IDP Guide Pack. Pretoria: Government Printers.

Geyer, Y. 2006. Integrated Development Planning: Handbook series for community-based organisations. IDASA.

Govender, J. \& Reddy, P.S. 2011. The imperative of participation in South African local government. Africanus, 41(2): 60-77.

Maphunye, K.J. \& Mafunisa, M.J. 2008. Public participation and integrated development processes in South Africa. Journal of Public Administration, 43(3.2): 461-472.

Malefane, S.R. \& Mashakoe, E. 2008. Integrated development planning (IDP) and local economic development (LED) in South Africa: The power-twins. Journal of Public Administration, 43(3.2): 473-482.

Maloka \& Mashamaite, 2013. Participation of government departments in the integrated development planning processes in Limpopo Province's local municipalities. 2013 SAAPAM Limpopo Chapter Conference Proceedings published by the South African Association and Management, p.p.195-201.

Mashamba, N.S. 2008. The state of IDP in the Limpopo Province. Journal of Public Administration, 43(3.2): 421-435.

Mautjana, H.M. \& Mtapuri, O. 2014. Integrated development plans without development indicators: Results from Capricorn District Municipalities in South Africa. Mediterranean Journal of Social- Sciences, 5(8), p.p: 474-483.

Mello, D.M. \& Maserumule, M.H. 2010. Intergovernmental relations and integrated development planning in South Africa. Journal of Public Administration, 45(1.1): 283-294.

Mzimakwe \& Reddy, 2008. Community participation in Ethekwini Municipality with particular reference to ward committees. Journal of Public Administration, 43(4.1): 667-679.

Njenga, 2009. A Critical Analysis of Public Participation in the Integrated Development Plans (IDP) of Selected Municipalities in Some Provinces (Gauteng, Eastern Cape, KwaZulu-Natal and Western Cape) in South Africa. Masters Mini-Dessertation, University of Kwa-Zulu Natal.

Phago, K. 2009. The integrated development plan in South African local government: The case of the City of Tshwane Metropolitan Municipality. Journal of Public Administration, 44(3): 483-491.

Public Service Commission (2008). Report on the Assessment of Public Participation Practices in the Public Service. Pretoria: Government Printers.

Republic of South Africa (1996). Constitution of the Republic of South Africa. 1996. Pretoria: Government Printer.

Republic of South Africa (2000). Local Government Municipal Systems Act, 2000 (Act 32 of 2000). Pretoria: Government Printer.

Republic of South Africa. 1998. Local Government: Municipal Structures Act, 1998 (Act 117 of 1998). Pretoria. Government Printers.

Republic of South Africa 1998. White Paper on Local Government. Ministry for Provincial Affairs and Constitutional Development. Pretoria: Government Printer.

Siyongwana, P. \& Mayekiso, T. 2011. Local Community and Stakeholder Participation in Post-Apartheid Urban Renewal Development Projects in Port Elizabeth, South Africa. Africa Insight 41 (3): 142-156.

Subban, M. \& Theron, H. 2012. Tracing a decade of drafting, reviewing and assessing integrated development plans in KwaZulu-Natal: Some key reflections. SSB/TRP/MDM, 61, p.p: 21-29.

Tshabalala, E.L. \& Lombard, A. 2009. Community participation in the integrated development plan: a case study of Govan Mbeki Municipality. Journal of Public Administration, 44(2): 396-409.

Valeta, L. \& Walton, G.K. 2008. Integrated development planning and budgeting at local government. Journal of Public Administration, 43(3.1): $373-384$. 